\title{
Surveillance of hospitalized farm injuries in Canada
}

\author{
W Pickett, L Hartling, H Dimich-Ward, J R Guernsey, L Hagel, D C Voaklander, R J Brison
}

Department of Emergency Medicine, Queen's University, Canada and Department of Community Health and Epidemiology, Queen's University, Canada W Pickett R J Brison

Department of Emergency Medicine, Queen's University, Canada

L Hartling

Department of Medicine, University of British Columbia, Canada

H Dimich-Ward

Department of Community Health and Epidemiology, Dalhousie University,

Canada

J R Guernsey

Centre for

Agricultural Medicine, University of Saskatchewan, Canada L Hagel

Department of Public Health Sciences, University of Alberta, Canada and Department of Rural Health, University of Melbourne, Australia D C Voaklander

Correspondence and requests for reprints to: $\mathrm{Dr}$ William Pickett, Department of Emergency Medicine,

Queen's University, Angada 3, Kingston General Hospital, 76 Stuart St, Kingston, Ontario, Canada K7L 2V7

PickettW@post.queensu.ca

\begin{abstract}
Objective-To provide an overview of hospital admissions for the treatment of farm injuries.

Methods-Design: descriptive analysis of data from the Canadian Agricultural Injury Surveillance Program (CAISP). Population: persons experiencing a farm injury requiring hospitalization, April 1991 to March 1995. Access to hospital separation data was negotiated within Canadian provinces. Individual cases were verified by medical records personnel and supplemental data describing injury circumstances were obtained. Analysis: descriptive analyses characterizing farm injuries by: persons involved, mechanisms, primary diagnoses, and agents of injury.

Results-Data from 8/10 Canadian provinces representing $98 \%$ of the farm population were obtained. A total of 8263 farm injuries were verified. Adults aged 60 years and older were over-represented in these injuries. Leading external causes of agricultural machinery injury included entanglements, being pinned/struck by machinery, falls, and runovers. Nonmachinery causes included falls from heights, animal related trauma, and being struck/by against objects. Leading diagnoses varied by age group, but included: limb fractures/open wounds, intracranial injuries, skull fractures, and spinal/ truncal fractures.
\end{abstract}

Conclusions-CAISP is a new agricultural injury surveillance program in Canada. Data from this system are actively used to inform prevention initiatives, and to indicate priorities for etiological and experimental research in the Canadian agricultural setting.

(Injury Prevention 2001;7:123-128)

Keywords: agriculture; farm; occupational; surveillance

Farming is one of the most dangerous occupations in Canada ${ }^{1}$ and involves exposure to a variety of hazards including unguarded machinery, animals, noise, dusts and airborne toxins, compressed air, and temperature extremes. ${ }^{2-7}$ While considerable attention has been devoted to modifying this environment in order to improve safety, ${ }^{7}$ newer agricultural practices have also introduced risks. Examples include spinal column fractures caused by large round bales, ${ }^{8}$ the physical risks associated with intensive livestock operations, ${ }^{9}$ acute poisoning and other toxicological effects of agrochemicals, ${ }^{10-12}$ oxygen deficient atmospheres or toxic gases, ${ }^{713}$ and contact with electrical devices and a wide variety of ergonomic hazards. ${ }^{714}$
The World Health Organization defines health surveillance as the ongoing and systematic collection, analysis, interpretation, and dissemination of health information. ${ }^{15}$ Injury surveillance is an important prevention activity in that it allows researchers to estimate the magnitude of injury related morbidity and mortality; detect new injury problems and changes in the occurrence of injury; and identify potential risk factors. ${ }^{15}{ }^{16}$ Data generated through surveillance initiatives provide a factual basis for the evaluation of intervention strategies, and for the development of rational public policies. ${ }^{1516}$

The Canadian Agricultural Injury Surveillance Program (CAISP) is one of the few existing national initiatives established to monitor farm injuries. Since 1996, CAISP researchers have established standard protocols for the identification and description of fatal $^{17}$ and hospitalized farm injuries, ${ }^{18}$ compiled registries of both types of injury; and described the occurrence of fatal ${ }^{117}$ and harvest related injuries ${ }^{19}$ as well as fatalities experienced by older farmers. ${ }^{20}$ The purpose of the present analysis is to provide a national description of hospitalized farm injuries. These analyses indicate priorities for the development and targeting of prevention efforts. To our best knowledge, the efforts of CAISP represent the first attempt to develop a national surveillance system of its type within any country outside Scandinavia $^{2122}$ and Australia. ${ }^{23} 24$

\section{Methods}

The CAISP data collection protocol for hospitalizations involves negotiating access to hospital separation data. Agencies responsible for data access vary, but include provincial Ministries of Health, Labour, and Agriculture, individual hospital boards, and Maritime Medical Care. Hospital separation records contain some personal identifiers, and where applicable, confidentiality agreements were established before data were released. The data collection protocol received human subjects approval at Queen's University.

Standard approaches to the identification of farm injuries were developed. Analyses were limited to acute, incident cases of injury identified using (International Classification of Diseases, 9th revision (ICD-9) E codes. ${ }^{25}$ Farm machinery injuries included those where the $\mathrm{E}$ code 919.0 (injuries caused by agricultural machinery) was listed on the hospital discharge record. Non-machinery farm injuries included those where: (1) a location of injury code indicated a farm as the location of injury (the fifth digit of the E code was 1); or (2) the accident location code (E849.1) indicated a farm and 
the E code was other than 919.0 ; or (3) a special location code indicated a farm work location (Manitoba only).

Descriptors available from the hospital records included: demographics, diagnostic code information, individual hospital identifiers and chart numbers (except in Saskatchewan), and data on lengths of hospital stay. Readmissions to a hospital for follow up injury treatment, rehabilitation, or long term care were excluded. Where more than one record was found for an injury event, only the initial treatment record was considered.

Supplemental data on all injury events were obtained. Provincial collaborators wrote each hospital (all provinces) and/or health district (Saskatchewan) and permission was sought to obtain medical chart data. Forms were then mailed to medical records departments where staff verified the injury record and abstracted additional information about external causes and circumstances of injury. Forms were returned and the new data combined with the basic record. Standard inclusion/exclusion criteria $^{18}$ and cleaning algorithms were applied to all records.

ANALYSIS

Cases were available for all but two provinces (Nova Scotia and Newfoundland/Labrador) and covered the five fiscal years ending 31 March 1995. Patterns of farm injury were characterized by: age group and sex, primary diagnoses; and mechanism and physical agent of injury. The latter analyses were stratified by class of external injury cause (machinery, nonmachinery) and presented for three broad age groups $(0-14,15-59,60+$ years $)$. MantelHaenszel $\chi^{2}$ tests $^{26}$ were used to assess statistical significance in comparing proportions between these age groups while adjusting for sex differences. Lengths of hospital stay within different case groups were described using medians and interquartile ranges (25th-75th centiles). Because of concerns about the inadequacy of available denominator data, it was not possible to calculate accurate rates of injury. Data management and analyses were done using Microsoft Access/Excel (Redmond, WA, Version 6.0, 1994), and SAS (Cary NC, Version 6.12, 1997).

Table 1 Hospitalized Farm Injuries in Canada April 1990 to March 1995, by age group and sex

\begin{tabular}{|c|c|c|c|c|c|}
\hline \multirow[b]{2}{*}{ Age group } & \multicolumn{2}{|l|}{ Machinery } & \multicolumn{2}{|c|}{ Non-machinery } & \multirow{2}{*}{$\begin{array}{l}\text { Farm population * } \\
\% \text { Of total } \\
(n=852435)\end{array}$} \\
\hline & $\begin{array}{l}\% \text { Of total } \\
(n=4042)\end{array}$ & $\begin{array}{l}\text { Sex ratio } \\
(m: f)\end{array}$ & $\begin{array}{l}\% \text { Of total } \\
(n=4221)\end{array}$ & $\begin{array}{l}\text { Sex ratio } \\
(m: f)\end{array}$ & \\
\hline $0-9$ & 7.6 & $3: 1$ & 7.6 & $2: 1$ & 15.4 \\
\hline $10-19$ & 12.8 & $8: 1$ & 12.3 & $2: 1$ & 18.5 \\
\hline $20-29$ & 10.3 & $10: 1$ & 10.9 & $3: 1$ & 11.1 \\
\hline $30-39$ & 15.3 & $10: 1$ & 18.2 & $3: 1$ & 14.7 \\
\hline $40-49$ & 15.3 & $8: 1$ & 16.6 & $3: 1$ & 14.8 \\
\hline 50-59 & 14.6 & $9: 1$ & 14.0 & $4: 1$ & 12.7 \\
\hline $60-69$ & 14.1 & $16: 1$ & 12.6 & $4: 1$ & 8.8 \\
\hline $70+$ & 9.9 & $39: 1$ & 7.8 & $3: 1$ & 4.0 \\
\hline Total & 100 & $9: 1$ & 100 & $3: 1$ & 100 \\
\hline
\end{tabular}

*Source: 1991 Canada Census of Agriculture. ${ }^{27}$

Note: direct comparisons of machinery and non-machinery injury counts should be avoided due to differential rates of case identification.
PREVENTION PRIORITIES

Priorities indicated from past fatal ${ }^{17}$ and the hospitalized CAISP injury data were identified separately for machinery and non-machinery injuries. Consideration was also given to child and adult priorities. Because of the existence of a unique E code (919.0), agricultural machinery priorities were based upon relatively complete data. The same is not true for non-machinery injuries, as these are identified by location of injury codes that are coded optionally. ${ }^{18}$ Care must be taken not to over-emphasize the importance of machinery relative to non-machinery priorities in these analyses.

\section{Results}

A total of 8263 hospitalized farm injuries were verified for the five years of study. The eight provinces included represented $98 \%$ of the Canadian farm population. ${ }^{27}$ Response rates to the requests for supplemental data averaged 97\% within provinces, and ranged from 93\%$99 \%$. The ratio of machinery:non-machinery injuries also varied by province (from 1:4 to $2: 1$ ), reflecting the extent of under-reporting in some provinces. All analyses presented are stratified by machinery/non-machinery causes and then presented as column percentages (tables 1-3), in order that undue emphasis was not placed upon machinery injuries within these analyses.

\section{AGE AND SEX}

When proportions of injuries within age groups were compared with the distribution of the Canadian farm population (table 1), children experienced fewer injuries than expected, while the proportion of injuries experienced by adults aged $60+$ was higher. Proportions experienced by the other age groups were consistent with the demographic distribution. This general pattern held for both machinery and nonmachinery types of injury. Table 1 also indicates a preponderance of male injuries in all age groups, with notable variations in the ratio of male:female injuries between machinery and non-machinery types. Males accounted for the vast majority of farm machinery injuries experienced in all age groups (the male:female ratio averaged 9:1). This sex ratio averaged 3:1 for non-machinery injuries.

\section{DIAGNOSES}

Farm machinery injuries often result in significant trauma and impairment (table 2). Among children, while the primary diagnoses were fractures and open wounds to the limbs, $15 \%$ involved internal injuries to the head. Leading types of injury observed in the adult age groups were fractures and open wounds to the limbs, as well as fractures to the spine or trunk. After adjustment for sex, proportions of injuries involving spine or trunk fractures, sprains/ strains, and open wounds to the upper limbs each increased with increasing age. Older farmers were less likely to experience skull and upper limb fractures, intracranial injuries, and open wounds to the head and lower limbs. 
Table 2 Hospitalized farm injuries in Canada, April 1990 to March 1995, by primary diagnosis and age group

\begin{tabular}{|c|c|c|c|c|c|c|c|c|c|c|c|}
\hline \multirow[b]{3}{*}{$\begin{array}{l}\text { Diagnostic } \\
\text { code }\end{array}$} & \multirow[b]{3}{*}{ Description of diagnostic code } & \multicolumn{5}{|c|}{ Machinery } & \multicolumn{5}{|c|}{ Non-machinery } \\
\hline & & \multirow[b]{2}{*}{ Injuries } & \multicolumn{3}{|c|}{ Age group (\% of column) } & \multirow[b]{2}{*}{$p$ Value $t$} & \multirow[b]{2}{*}{ Injuries } & \multicolumn{4}{|c|}{ Age group (\% of column) } \\
\hline & & & $\begin{array}{l}0-14 \\
(n=513)\end{array}$ & $\begin{array}{l}15-59 \\
(n=2558)\end{array}$ & $\begin{array}{l}60+ \\
(n=971)\end{array}$ & & & $\begin{array}{l}0-14 \\
(n=581)\end{array}$ & $\begin{array}{l}15-59 \\
(n=2780)\end{array}$ & $\begin{array}{l}60+ \\
(n=860)\end{array}$ & $p$ Value $t$ \\
\hline $800-804$ & Fracture: skull & 100 & 4.5 & 2.3 & 1.9 & 0.005 & 180 & 5.0 & 4.8 & 2.2 & 0.003 \\
\hline 805-809 & Fracture: spine and trunk & 358 & 4.7 & 7.7 & 14.1 & 0.001 & 353 & 1.0 & 8.5 & 12.8 & 0.001 \\
\hline $810-819$ & Fracture: upper limb & 636 & 19.3 & 16.5 & 11.7 & 0.001 & 445 & 23.4 & 9.0 & 7.0 & 0.001 \\
\hline $820-829$ & Fracture: lower limb & 568 & 15.6 & 14.2 & 13.0 & 0.469 & 637 & 9.6 & 14.6 & 20.5 & 0.001 \\
\hline $830-839$ & Dislocation & 82 & 0.8 & 2.3 & 2.1 & 0.104 & 147 & 1.0 & 4.1 & 3.3 & 0.001 \\
\hline $840-848$ & Sprains/strains of joints and adjacent muscles & 104 & 0 & 2.8 & 3.4 & 0.001 & 289 & 0.9 & 7.9 & 7.6 & 0.001 \\
\hline \multirow[t]{2}{*}{$850-854$} & Intracranial injury, excluding those with skull & & & & & & & & & & \\
\hline & fracture & 170 & 10.5 & 3.4 & 2.9 & 0.001 & 353 & 17.2 & 6.9 & 7.1 & 0.001 \\
\hline $860-869$ & Internal injury of chest, pelvis, and abdomen & 125 & 3.3 & 2.7 & 3.9 & 0.214 & 128 & 2.8 & 3.1 & 3.1 & 0.875 \\
\hline $870-879$ & Open wound: head, neck, and trunk & 120 & 5.3 & 2.6 & 2.8 & 0.003 & 112 & 5.3 & 2.5 & 1.4 & 0.001 \\
\hline $880-887$ & Open wound: upper limb & 655 & 10.5 & 17.6 & 15.6 & 0.001 & 153 & 2.1 & 4.5 & 1.9 & 0.001 \\
\hline $890-897$ & Open wound: lower limb & 225 & 6.6 & 6.1 & 3.7 & 0.009 & 121 & 3.4 & 3.0 & 2.2 & 0.316 \\
\hline $900-904$ & Injury to blood vessels & 12 & 0.2 & 0.3 & 0.3 & 0.946 & 9 & 0 & 0.3 & 0.2 & 0.514 \\
\hline 910-919 & Superficial injury & 30 & 1.6 & 0.7 & 0.5 & 0.272 & 40 & 1.6 & 0.9 & 0.8 & 0.250 \\
\hline $920-924$ & Contusion with intact skin surface & 202 & 5.5 & 4.5 & 6.2 & 0.083 & 261 & 4.1 & 6.2 & 7.4 & 0.022 \\
\hline $925-929$ & Crushing injury & 196 & 4.7 & 5.3 & 3.8 & 0.159 & 35 & 0.5 & 1.0 & 0.4 & 0.104 \\
\hline $940-949$ & Burns & 50 & 0.6 & 1.6 & 0.6 & 0.022 & 176 & 6.4 & 3.9 & 3.6 & 0.003 \\
\hline $950-957$ & Injury to nerves and spinal cord & 30 & 0.6 & 0.7 & 0.9 & 0.655 & 18 & 0.2 & 0.5 & 0.2 & 0.303 \\
\hline \multirow[t]{5}{*}{ 958-959 } & Certain traumatic complications and & & & & & & & & & & \\
\hline & unspecified injuries & 188 & 3.1 & 4.7 & 5.5 & 0.084 & 161 & 2.6 & 4.0 & 4.1 & 0.261 \\
\hline & Other & 190 & 2.7 & 4.2 & 7.1 & 0.001 & 596 & 12.9 & 14.4 & 14.2 & 0.857 \\
\hline & Missing & 1 & 0 & 0 & 0.1 & 0.231 & 1 & 0 & 0.2 & 0.1 & 0.509 \\
\hline & Total & 4042 & & & & & 4221 & & & & \\
\hline
\end{tabular}

${ }^{\star}$ Based on the nature of injury code from ICD-9-CM. ${ }^{25}$

tp Value: Mantel-Haenszel test for differences in proportions between age groups with adjustment for sex. ${ }^{26}$

Note: direct comparisons of machinery and non-machinery injury counts should be avoided due to differential rates of case identification.

Non-machinery causes also led to substantial injuries (table 2). Demographic trends in diagnoses were very similar to injuries caused by machinery.

\section{EXTERNAL CAUSES}

Four external causes accounted for greater than $75 \%$ of all machinery related injuries in each of the three age groups (table 3). Runovers and motor vehicle collisions were most common among children, while all other mechanisms of injury were more common in the adult age groups. With respect to the machines involved, farm tractors accounted for $27.9 \%$ of the farm machinery injuries, followed by combines $(8.6 \%)$, grain augers $(6.4 \%)$, power-take-off

Table 3 Hospitalized farm injuries in Canada, April 1990 to March 1995, by circumstance and age group

\begin{tabular}{|c|c|c|c|c|c|}
\hline \multirow[b]{2}{*}{ Circumstance } & \multirow{2}{*}{$\begin{array}{l}\text { No (\%) } \\
\text { injuries }\end{array}$} & \multicolumn{4}{|c|}{ Age group (\% of total) } \\
\hline & & $0-14$ & $15-59$ & $60+$ & $p$ Valuet \\
\hline Machinery & & $n=513$ & $n=2558$ & $n=971$ & \\
\hline Entanglement/caught in & $1360(33.6)$ & 29.4 & 36.9 & 27.4 & 0.001 \\
\hline Pinned or struck by machine & $816(20.2)$ & 14.4 & 22.0 & 18.5 & 0.001 \\
\hline Fell from machine, not runover & $611(15.1)$ & 19.1 & 12.5 & 19.8 & 0.001 \\
\hline Runover & $420(10.4)$ & 21.1 & 7.5 & 12.3 & 0.001 \\
\hline Struck by falling or projected object & $214(5.3)$ & 2.9 & 5.8 & 5.3 & 0.011 \\
\hline Rollover & $201(5.0)$ & 3.5 & 4.7 & 6.6 & 0.039 \\
\hline Motor vehicle collision & $43(1.1)$ & 3.5 & 0.8 & 0.4 & 0.001 \\
\hline Other/unknown & $377(9.3)$ & 6.0 & 9.8 & 9.8 & 0.015 \\
\hline Total & $4042(100)$ & 100 & 100 & 100 & \\
\hline Non-machinery & & $n=581$ & $n=2780$ & $n=860$ & \\
\hline Fall & $1034(24.5)$ & 31.2 & 20.1 & 34.3 & 0.001 \\
\hline Animal & $1578(37.4)$ & 36.0 & 38.7 & 34.1 & 0.018 \\
\hline Struck by/against object & $699(16.6)$ & 14.6 & 18.0 & 13.3 & 0.003 \\
\hline Overexertion & $265(6.3)$ & 0.2 & 7.4 & 6.9 & 0.001 \\
\hline Radiation, toxic/noxious substances & $246(5.8)$ & 5.7 & 6.6 & 3.5 & 0.003 \\
\hline Fire & $129(3.1)$ & 4.3 & 2.7 & 3.3 & 0.059 \\
\hline Caught in/under/between objects & $89(2.1)$ & 1.0 & 2.5 & 1.6 & 0.056 \\
\hline Temperature extremes & $32(0.8)$ & 1.9 & 0.5 & 0.8 & 0.042 \\
\hline Electric current & $22(0.5)$ & 0 & 0.7 & 0.2 & 0.003 \\
\hline Other/unknown & $127(3.0)$ & 5.2 & 2.8 & 2.1 & 0.001 \\
\hline Total & $4221(100)$ & 100 & 100 & 100 & \\
\hline
\end{tabular}

${ }^{\star} \mathrm{p}$ Value: Mantel-Haenszel test for differences in proportions between age groups with adjustment for sex. ${ }^{26}$

Note: direct comparisons of machinery and non-machinery injury counts should be avoided due to differential rates of case identification. devices $(5.4 \%)$, motor vehicles $(5.4 \%)$, and balers $(3.9 \%)$. Common mechanisms of tractor injury were runovers $(26.5 \%$ of the 1127 tractor injuries), being pinned or struck by a tractor $(19.7 \%)$, falls $(18.0 \%)$, and tractor rollovers $(11.4 \%)$. Entanglement/caught in was the leading mechanism of injury associated with various types of machinery as follows: combines (43.0\% were entanglement/caught in injuries), power-take-off devices $(96.8 \%)$, balers $(58.2 \%)$, harvesters $(74.4 \%)$, and hay elevators $(62.1 \%)$. Falls from equipment were important mechanisms of injury for several machinery classes, most notably for tractors $(18.0 \%$ were fall injuries), combines (34.4\%), motor vehicles $(41.1 \%)$, and farm wagons $(41.3 \%)$.

Among non-machinery injuries (table 3), falls, animal related trauma, and being struck by/against an object were common to all age groups. Falls were especially prominent among children/youth and older adults, while animal related trauma, being struck by/against objects, overexertion injuries and poisonings were more common in the $15-59$ year age group.

LENGTHS OF HOSPITAL STAY

Initial lengths of stay as inpatients for the treatment of farm injuries were calculated for various combinations of injury type (machinery/ non-machinery), age group, mechanism of injury, and machinery class (agent of injury). The most severe categories of injury, as indicated by higher lengths of stay (median days; interquartile ranges) were, by mechanism: runovers (5 days; 2-13), rollovers (4; $2-8)$; exposure to fires and temperature extremes $(4 ; 1-10)$; by machine: power-take-off (6; 2-11), tractor $(4 ; 2-9)$, and harvester (4; $2-9)$ injuries; and by age: injuries to those aged $60+$ years $(4 ; 2-10)$. 
Table 4 Injury prevention priorities identified by the CAISP: machinery injuries

\begin{tabular}{|c|c|c|c|c|}
\hline & \multicolumn{4}{|c|}{ Relative priority* } \\
\hline & \multicolumn{2}{|c|}{ CAISP fatality data ${ }^{17}$} & \multicolumn{2}{|c|}{ CAISP hospital data } \\
\hline & $\begin{array}{l}\text { Children } \\
0-14 \text { years }\end{array}$ & $\begin{array}{l}\text { Adults ages } \\
15+\end{array}$ & $\begin{array}{l}\text { Children } \\
0-14 \text { years }\end{array}$ & $\begin{array}{l}\text { Adults ages } \\
15+\end{array}$ \\
\hline Entanglement/caught in & - & + & +++ & +++ \\
\hline Pinned or struck by machine & - & + & + & + \\
\hline Fell from machine, not runover & - & - & + & + \\
\hline Runover & +++ & + & + & + \\
\hline Struck by falling or propelled object & - & - & - & + \\
\hline Rollover & + & +++ & - & + \\
\hline
\end{tabular}

^Key: - low priority: $<5 \%$ of fatal or hospitalized machinery injuries, respectively; + medium priority: $5.0-24.9 \%$; +++ high priority: $25.0 \%$ or more.

Table 5 Injury prevention priorities identified by the CAISP: non-machinery injuries

\begin{tabular}{|c|c|c|c|c|}
\hline & \multicolumn{4}{|c|}{ Relative priority ${ }^{\star}$} \\
\hline & \multicolumn{2}{|c|}{ CAISP fatality data $^{17}$} & \multicolumn{2}{|c|}{ CAISP hospital data } \\
\hline & $\begin{array}{l}\text { Children } \\
0-14 \text { years }\end{array}$ & $\begin{array}{l}\text { Adults ages } \\
15+\end{array}$ & $\begin{array}{l}\text { Children } \\
0-14 \text { years }\end{array}$ & $\begin{array}{l}\text { Adults ages } \\
15+\end{array}$ \\
\hline Fall from height & + & + & +++ & + \\
\hline Fall on same level & - & - & - & + \\
\hline Animal contact & + & + & +++ & +++ \\
\hline Struck by/against object & + & + & + & + \\
\hline Overexertion & _- & _- & - & + \\
\hline Drowning & +++ & - & - & - \\
\hline
\end{tabular}

${ }^{\star} \mathrm{Key}$ : - low priority: $<5 \%$ of fatal or hospitalized non-machinery injuries, respectively; + medium priority: $5.0-24.9 \%$; +++ high priority: $25.0 \%$ or more.

\section{PRIORITIES}

Table 4 summarizes the leading injury patterns that emerged from analyses of both fatal ${ }^{117}$ and hospitalized CAISP cases of agricultural machinery injury. These were runovers, entanglement/caught in injuries (children), and rollovers and entanglement injuries (adults).

Table 5 presents the priorities for nonmachinery injuries. The latter included drownings (children), ${ }^{17}$ falls from heights (children), and animal related trauma (children and adults).

\section{Discussion}

This report presents information from a nationwide surveillance system for agricultural injuries in Canada for the period April 1990 to March 1995. There were 1655 hospitalizations identified annually (808 and 844 for machinery and non-machinery types) for our national population of 852 thousand farm residents. ${ }^{27}$ The existence of a specific ICD E code (919.0) for farm machinery injuries helped in their accurate identification. The numbers of nonmachinery injuries identified are substantial underestimates, although we would argue that the patterns of injury observed within these injuries are likely to be representative.

\section{PATTERNS OF FARM INJURY}

Fractures and open wounds to the limbs were the most frequent result of machinery related trauma. All farm injuries were experienced more often by males than females. Children were more likely to experience serious skull fractures and intracranial injuries. Case descriptions indicate that these are often attributable to mechanized and structural farm hazards present in the farm environment, such as poorly guarded machinery, and the lack of barriers to prevent children from being exposed to mechanized equipment, and to animal and fall hazards. It is also possible that age related differences exist in the diagnosis and clinical management of head injuries, and these account for the excesses in hospitalizations among children.

Adults on farms also experience a wide variety of serious trauma, with fractures and open wounds from entanglements, runovers, animals, and falls predominating. Proportionally more spinal fractures and lower limb fractures were notable in the older age group. This and their relatively long lengths of hospital stay suggest that older farmers experience injuries that are relatively severe.

Common farm hazards observed in the Canadian childhood cases include exposures to operating vehicles and equipment, large animals, and structural fall hazards. Supervision of many injured children was quite likely to be inadequate in many circumstances, most notably during the summer months. Case descriptions indicate the lack of passive barriers on many farms including guards on machinery, fences to keep children at a distance from operating equipment, ponds and lagoons, protective railings, and animal containment systems. Because our analysis was descriptive, the strength of these risk factors cannot be quantified. There is a dearth of analytic studies in the agricultural health and safety literature, and the few case-control and cohort studies that exist have not examined passive barriers and their presence/absence as risk factors for farm injury.

CAISP: IMPORTANCE FOR INJURY PREVENTION

The establishment of a nationwide data collection protocol and coordinated system for the surveillance of farm injuries in Canada (CAISP) was a notable achievement. Results from this initiative provide direction for prevention, as well as etiologic and experimental research. By pooling data from multiple sources, CAISP provides national evidence about the magnitude of the problem, potential intervention priorities, and patterns of injury that could not be identified in more regional analyses. Some of these were known and therefore confirmed by these analyses, for example, tractor runovers among children ${ }^{28}{ }^{29}$; rollovers in adults ${ }^{117}{ }^{10}$; and machinery entanglements in all ages. ${ }^{18}{ }^{31}$ New injury patterns also emerged. Among children, these included falls from structures and other heights, and animal related trauma. The latter was also identified as a leading causes of adult farm injury.

Review of published literature suggests that, as a national system, CAISP is unique because of its attempts to provide complete coverage of fatal and hospitalized agricultural injuries, and because of the comprehensiveness of the data collected for external causes of injury. Published national analyses from the United States have been based on occupational systems that focus on fatalities exclusively (generally among adults; for example, Bell et $a l^{6}$ and Myers and $\mathrm{Hard}^{32}{ }^{33}$ ), national farm health surveys (for example, Myers et $a l^{2}$ and Hoskin and Miller ${ }^{4}$ ), and for children, electronic death certificate 
data $^{34}$ and the NEISS emergency department system that focuses upon injuries caused by consumer products. $^{34}$ Published surveillance data from Scandinavia has focused upon fatalities $^{21}$ and emergency department surveillance systems. ${ }^{22}$ In Australia, there is an emerging coronial injury surveillance system that will involve prospective case identification of farm fatalities, as well as recent national reports on general farm ${ }^{23}$ and tractor related ${ }^{24}$ fatalities for 1989-92. These reports are analogous to those from CAISP in terms of comprehensiveness, but have the added benefit of being able to describe injury patterns within farm commodity groups. To our best knowledge Australia and other countries do not yet have national systems for the surveillance of hospitalized and other forms of non-fatal farm injury, making CAISP a unique surveillance initiative.

To date, CAISP data have been applied to a number of prevention and research initiatives. These include: (1) establishment of national prevention priorities adopted by our national farm/rural safety coalition; (2) support for the establishment of provincial farm safety agendas/policies (governmental and nongovernmental); (3) providing a factual basis for national and regional information campaigns, including those associated with Canada's Farm Safety Week; (4) the supply of requisite data to inform the development of a case-control study of risk factors for agricultural machinery injury in the prairie provinces; (5) specific data/ analyses to help organizations (for example, the Canadian Federation of Agriculture, the Canadian National Institute for the Blind, Farmers with Disabilities) in the development of new prevention initiatives, and the evaluation of existing resources (for example, the North American Guidelines for Children's Agricultural Tasks $^{35}$ ).

While all of these developments are positive, there is admittedly no evidence available to show whether they contribute to lower injury rates. Further, CAISP data in themselves do not indicate optimal farm injury prevention strategies. This points to the need for new research initiatives in Canada and internationally that compare the injury experiences of farm populations that operate under different regulatory approaches, randomized controlled trials that establish the efficacy of interventions, and systematic reviews that synthesize this evaluative evidence, as it emerges. Provided that the CAISP initiative is sustained, it will provide researchers with a viable source of outcome data to be used in the evaluation of these initiatives.

Common approaches to agricultural injury prevention that may require surveillance data for their evaluation include: (1) legislative regulation of the farm work environment; (2) installation of protective structures and/or devices and other environmental changes; and, (3) educational campaigns. In Canada, legislative strategies common to other occupational settings have not, or cannot, be universally applied to the agricultural industry. The reality is that changes to the farm work environment are typically left to the discretion of the individual owner-operator, and there is a heavy reliance on voluntary safety standards and educational approaches. These include initiatives such as: the development of guidelines meant to assist parents in the appropriate matching of children to farm work tasks, ${ }^{35} 36$ enhanced daycare options, ${ }^{37} 38$ tractor certification and other training modules, ${ }^{37} 38$ and farm safety day camps. ${ }^{37}{ }^{38}$ This can be contrasted with the experience in Scandinavian countries, ${ }^{39}$ where comprehensive prevention strategies are developed "with" (as opposed to "for") farmers, and there appears to be more tolerance of legislative initiatives. The latter programs include the provision of adequate support services (for example, rural daycare) throughout the year, the development of medical services tailored to farmers, and the introduction of safer equipment and structures designed by/with farmers for the industry. In Canada, optimal approaches to the prevention of injuries on farms remain elusive in the absence of enforced legislative and/or other comprehensive strategies.

\section{LIMITATIONS OF CAISP}

Finally, some important limitations of CAISP and this analysis must be recognized. Data from two smaller Atlantic provinces (Nova Scotia, Newfoundland/Labrador), although part of the program, were not available at the time this analysis. In provinces where data did exist, the accuracy of our data was dependent upon the vigilance of medical record personnel during the data verification/abstraction stage, and whether they were familiar with agricultural practices and terminology. Steps were taken, however, to minimize bias at this stage of the process. Unfamiliarity with agricultural practices was mitigated by asking for written descriptions of injury circumstances. These were used to verify supplemental coding. The use of hospital records as the sole data source did prevent us from assessing the roles of injury victims, activities being undertaken and salient risk factors for injury such as the use of passive safety devices or equipment modification.

\section{Conclusion}

To our best knowledge, the CAISP program represents the first North American attempt to develop a national system for the surveillance of hospitalized farm injuries. These data add substantially to the existing knowledge from analyses of fatalities in that certain farm injury patterns are different and provide insight into important new priorities for intervention. The approach to data collection was highly efficient. Considerable efforts were made to standardize the process of case identification, perform supplemental data collection, verify case records and apply standard inclusion/exclusion criteria to each, code each record according to a standard system, and finally pool these data for analytical purposes. These represent the first steps in an evolving process, and it is our hope that CAISP will continue to develop as a resource for prevention and research. 


\section{Key points}

- Agricultural injuries are an injury control problem with global importance.

- There are few national systems for the ongoing surveillance of agricultural injuries.

- The Canadian Agricultural Injury Surveillance Program (CAISP) is a new surveillance program that systematically collects and interprets information on fatal and hospitalized forms of farm injury.

- The present analysis identifies leading causes of hospitalized farm injury in Canada. CAISP is the only national program in existence that systematically compiles data about fatal and hospitalized forms of farm injury.

- Data from the CAISP system are actively used to inform prevention initiatives, and to indicate priorities for etiological and experimental research.

The CAISP group would like to thank the following individuals for their contributions: A Dy Buncio, S Peck (British for their contributions: A Dy Buncio, S Peck (British
Columbia); M R Stang (Saskatchewan Health); G Mackenzie Columbia); M R Stang (Saskatchewan Health); G Mackenzie
(Nova Scotia); E Crouse (Nova Scotia), Nova Scotia Farm (Nova Scotia); E Crouse (Nova Scotia), Nova Scotia Farm Department of Health), Y Rideout (Newfoundland/Labrador Department of Health), Y Rideout (Newfoundland/Labrador
Federation of Agriculture). In addition to the authors, the Federation of Agriculture). In addition to the authors, the
following institutions and persons participate in the Canadian Agricultural Injury Surveillance Program: S Kyeremanteng Farm Safety Program, Alberta Agriculture Food and Rural Development; D Schopflocher, Surveillance Branch, Alberta Health; K Belton, Alberta Centre for Injury Control and Research, D Rennie, Centre for Agricultural Medicine, University of Saskatchewan; T Redekop, N Alberg: Manitoba Department of Labour, Occupational Health Branch; L Paré, B. Gingras: Direction de la santé publique Chaudière-Appalaches; B C Balram, E Bastin: Provincial Epidemiology Service, New Brunswick Department of Health and Community Services; $M$ Affleck, Prince Edward Island Federation of Agriculture; Affleck, Prince Edward Island Federation of Agriculture; T $\mathrm{T}$ Arbuckle: Laboratory Centre for Disease Control, Health Canada.

CAISP is funded and supported by the Canadian Agriculture Safety Program, Agriculture and Agri-Food Canada which is Safety Program, Agriculture and Agri-Food Canada which is
administered by the Canadian Coalition for Agricultural Safety administered by the Canadian Coalition for Agricultural Safety
and Rural Health. Dr Pickett is a Career Scientist funded by the and Rural Health. Dr Pickett is a Career Scientist funded by the Ontario Ministry of Health and Long-Term Care. This study is
based in part on data from provincial Departments/Ministries of based in part on data from provincial Departments/Ministries of do not necessarily represent those of these provincial governments or Departments/Ministries of Health. Human subject approval for CAISP was granted by the Queen's University Health Sciences Research Ethics Board.

1 Pickett W, Hartling L, Brison RJ, et al. Fatal work-related farm injuries in Canada, 1991-1995. Canadian Agricultural Injury Surveillance Program. Can Med Assoc $f$ 1999;160:1843-8.

2 Myers JR, Hard DL, Snyder KA, et al. Risks of fatal injuries to farm workers 55-years of age and older. Am $\mathcal{f}$ Ind $\mathrm{Med}$ 1999;suppl 1:29-30.

3 Hopkins RS. Farm equipment injuries in a rural county, 1980 through 1985: the emergency department as a source of data for prevention. Ann Emerg Med 1989;18:758-62.

4 Hoskin AF, Miller RA. Farm accident surveys: a 21-state summary with emphasis on animal-related injuries. $\mathcal{F}$ Safety Res 1979;21:2-13.

5 Cordes DH, Rea DF. Farming: a hazardous occupation. Occup Med 1991;6:327-34.

6 Bell CA, Stout NA, Bender TR, et al. Fatal occupational injuries in the United States, 1980 through 1985. FAMA 1990;263:3047-50.

7 Murphy DJ. Safety and health for production agriculture. St Joseph, MI: American Society of Agricultural Engineers, 1992.

8 Mayba II. Hay balers fractures. F Trauma 1984;24:271-3.

9 Khachatourians GG. Agricultural use of antibiotics and the evolution and transfer of antibiotic-resistant bacteria. Can Med Assoc F 1998;159:1129-36.
10 Mushak EW, Piver WT. Agricultural chemical utilization and human health. Environ Health Perspect 1992;97:269and 74.

11 Kuiper HA. The role of toxicology in the evaluation of new agrochemicals. F Environ Sci Health B 1996;31:353-63.

12 Garcia AM. Occupational exposure to pesticides and congenital malformations: a review of mechanisms, methods, and results. Am F Ind Med 1998;33:232-40.

13 Donham KJ, Knapp LW, Monson R, et al. Acute toxic exposure to gases from liquid manure. $\mathcal{F}$ Occup Med 1982;24: $142-5$.

14 Kay K. Agricultural health and hygiene-with a special reference to the Canadian position. Environ Res 1971;4:44068.

15 Klaucke DN, Buehler JW, Thacker SB, et al. Guidelines for evaluating surveillance systems. MMWR Morb Mortal Wkly Rep 1988;37(suppl 5):1-18.

16 Thacker SB, Stroup DF. Future directions for comprehensive public health surveillance and health information systems in the United States. Am $\mathcal{F}$ Epidemiol 1994;140:38397.

17 Brison RJ, Pickett W, Hartling L. Fatal farm injuries in Canada. Report from the Canadian Agricultural Injury Surveillance Program. Saskatoon: Canadian Coalition for Agricultural and Rural Safety and Health, 1998.

18 Pickett W, Brison RJ, Hartling L, et al. Hospitalized farm injuries in Canada: 1990-96. Report from the Canadian Agricultural Injury Surveillance Program. Saskatoon: Canadian Coalition for Agricultural and Rural Safety and Health, 1999 .

19 Hartling L, Pickett W, Guernsey JR, et al. Injuries associated with the farm harvest in Canada. Can Med Assoc 7 1998;158:1493-6.

20 Voaklander DC, Hartling L, Pickett W, et al. Work-related mortality among older farmers in Canada. Can Fam Physician 1999;45:2903-10.

21 Notkola VJ, Husman KR, Laukkanen VJ. Mortality among male farmers in Finland 1979-83. Scand f Work Environ Health 1987;13:124-8.

22 Jansson BR. The yield of systems for continuous and periodic injury surveillance in emergency care with emphasis on farm-work-related accidents. Scand F Soc Med 1987; 15:247-52.

23 Franklin R, Mitchell R, Dricoll T, et al. Farm-related fatalities in Australia, 1989-92. Moree: ACAHS, NOHSC \& RIRDC, 2000.

24 National Occupational Health and Safety Commission NOHSC). Work-related fatalities involving tractors in Australia, 1989 to 1992 . Sydney: NOHSC, 2000.

25 World Health Organization. Manual of the international classification of diseases, injuries, and causes of death. 9th Revision. Geneva, Switzerland: WHO, 1977.

26 Rosner BA. Fundamentals of biostatistics. 4th Ed. Belmont, California: Duxbury Press, 1995: 362-3.

27 Statistics Canada. 1991 Canada census of agriculture. Ottawa: Ministry of Supplies and Services, 1992.

28 Pickett W, Brison RJ. Tractor-related injuries in Ontario. Can F Public Health 1995;86:243-6.

29 Pickett W, Brison RJ, Hoey JR. Fatal and hospitalized agricultural machinery injuries to children in Ontario, Canada. Inj Prev 1995;1:97-102.

30 Brison RJ, Pickett W. Fatal farm injuries in Ontario, 1984 through 1992. Can f Public Health 1995;86:246-8.

31 Hartling L, Pickett W, Brison RJ. Non-tractor agricultural machinery injuries in Ontario. Can $\mathcal{f}$ Public Health 1997;88:32-5.

32 Myers JR. National surveillance of occupational fatalities in agriculture. Am F Ind Med 1990;18:163-8.

33 Myers JR, Hard DL. Work-related fatalities in the agricultural production and services sectors, 1980-1989. Am F Ind Med 1995;27:51-63.

34 Rivara FP. Fatal and non-fatal farm injuries to children and adolescents in the United Sates, 1990-3. Inj Prev 1997;3:190-4.

35 Tevis C. North American guidelines for children's agricultural tasks: helping kids to the job safely. Successful Farming May-June 1999

36 Lee B, Marlenga B, eds. Professional research manual: North American guidelines for children's agricultural tasks. Marshfield, WI: Marshfield Clinic, 1999.

37 National Committee for Childhood Agricultural Injury Prevention. Children and agriculture: opportunities for safety and health. Marshfield, WI: Marshfield Clinic, 1996.

38 National Institute for Occupational Safety and Health. Request for applications: childhood agricultural safety and Disease Control, 2000 (http://grants.nih.gov/grants/guide/ rfa-files/RFA-OH-00-001.html).

39 Palermo T, Ehlers, J. Community partners for healthy farming intervention. Abstract O148: Fourth International Symposium: Rural Health and Safety in a Changing World, Saskatoon, Canada: University of Saskatchewan, 18-22 October 1998 